None declared, Tomoya Nishino: None declared, Atsushi Kawakami Grant/ research support from: Astellas Pharma, Consultant for: Astellas Pharma, Speakers bureau: Astellas Pharma

DOI: 10.1136/annrheumdis-2019-eular.2595

\section{THU0274 QUALITATIVE AND QUANTITATIVE ANALYSIS OF THE INMUNOLOGIC CHARACTERISTICS OF THE MINOR SALIVARY GLAND BIOPSY IN SJÖGREN'S SYNDROME}

HYE SANG PARK ${ }^{1}$, Laura Martinez-Martinez ${ }^{1}$, Berta Magallares ${ }^{1,2}$, Ivan Castellví ${ }^{1}$, Cesar Díaz-Torné $^{1}$, Ana Laiz ${ }^{1}$, Patricia Moya ${ }^{1,2}$, Ana Milena Millán Arciniegas ${ }^{1}$, Andrea García-Guillén ${ }^{1}$, Sycille Jeria ${ }^{1}$, David Lobo ${ }^{1}$, Susana P. FernandezSanchez $^{1}$, Conxita Pitarch ${ }^{2}$, Manel Riera ${ }^{2}$, Maria Carmen Hernandez Lafuente ${ }^{1}$, Cándido Juarez', Hector Corominas ${ }^{1} .{ }^{1}$ HOSPITAL DE LA SANTA CREU I SANT PAU, BARCELONA, Spain; ${ }^{2}$ HOSPITAL DOS DE MAIG, BARCELONA, Spain

Background: Minor salivary gland biopsy (MSGB) is the most important diagnostic test of Sjögren's Syndrome (SS). It demonstrates the presence of the inflammatory infiltration in the most affected site. It's possible role as a biomarker in the disease is still unknown. The Inmunology Department of our center conducts a detailed analysis of the MSGB about the leukocyte infiltration and quantifies number of each cell.

Objectives: To describe the inmunologic features of the MSGB and carry out an association analysis with clinical variables

Methods: Clinical variables, ESSDAI index at the moment of diagnosis and laboratory parameters were recorded. As from the MSGB, number of infiltration focus (1, 2 or several), big infiltrations (>100 cells), number of $B$ and $T$ cells, CD4/CD8 ratio and presence of isolated lymphocyte were collected. Categorical variables were described as frequencies and analysed using Fisher exact test. $T$ student and Wilcoxon Rank Sum Test were used for comparison of means $(\mu)$.

Results: In 2017, a total of 104 MSGB were carried out in our center. Among them 58 were diagnosed as SS by medical and ACR/EULAR 2016 criteria. Finally 41 patients with SS and abnormal MSGB result were included for this study.

\begin{tabular}{lc}
\hline Basal characteristics of patients & Frequency \\
\hline Men & $8 / 19,5 \%$ \\
Extraglandular disease & $18 / 43,9 \%$ \\
ESSDAl $\geq 2$ & $17 / 41,46 \%$ \\
Other autoinmune diseases & $2 / 4,87 \%$ \\
Ac. Ro/La & $0 / 0$ \\
CRP & $13 / 31,71 \%$ \\
& $(\mu 9,79 \mathrm{mg} / \mathrm{dL}$ ) \\
ANA pattern & $8 / 19,51 \%$ \\
Negative & $1 / 2,44 \%$ \\
Homogenous & $16 / 39,02 \%$ \\
Speckled & $10 / 24,39 \%$ \\
Speckled and Homogeneous & $6 / 14,64 \%$ \\
Other &
\end{tabular}

Biopsy: Patients with active disease (ESSDAI $\geq 2$ ) had greater amount of cells ( $\mu 159$ cells vs 509 cells; $p=0,055$ ) as well as those with extraglandular disease ( $\mu 160$ vs 488; $p=0.08$ ). Patients with active disease also had larger number of infiltration focus $(p=0.062)$. The presence of isolated CD8+ $\mathrm{T}$ cells was observed in 13 patients and they had lesser cells ( $\mu 136$ vs $381 ; p=0.35$ ). In those samples with predominance of $T$ cells over B cells had larger number of infiltrate focus $(7 / 20 ; 35 \%$ vs 12 / $21 ; 57.14 \% ; \mathrm{p}=0.155)$. No association with disease activity or extraglandular manifestation was found.

Extraglandular manifestation and disease activity: 18 patients had extraglandular disease. Moderate or severe ESSDAI activity was found in 14 of these patients $(34.2 \%, p=0.00)$. The biopsy of patients with extraglandular disease had larger amount of cells ( $\mu 200$ vs 145; $p=0.01$ ). Patients with active disease had more infiltratre focus (6/22 vs $11 / 19 ; p=0.047$ ). Disease evolution time was similar with a mean duration of 8-9 years in both groups.

Corticosteroids: There were 3 patients with active steroid treatment ( $\geq$ prednisone $10 \mathrm{mg} / \mathrm{d}$ ) at the moment of the biopsy. All 3 of them had $>1$ focus in the sample and 2 of them had large infiltrate with $>150$ cells. Eight of them had received steroids in the last 5 years, 6 of them had large infiltate with $>150$ cells and 4 had $>1$ infiltrate focus in the biopsy. A study with more sample should be carried out to study the influence of steroids in the biopsy results.

Conclusion:

- Patients with extraglandular disease have larger amount of cells in the composition of infiltration. Those with more disease activity had more number of infiltration focus.
- In 14 patients specific antibodies and antinuclear antibodies were negative. In these patients the biopsy is the most useful diagnostic test.

- Possible association of those variables that were statistically not signifcant should not be ruled out due to the small sample size of the study.

Disclosure of Interests: HYE SANG PARK: None declared, LAURA MARTINEZ-MARTINEZ: None declared, Berta Magallares: None declared, Ivan Castellví Consultant for: I received fees less than 5000USD as a consultant for Kern and Actelion, Paid instructor for: I received fees less than 2000USD as a instructor for Boehringer -Ingelheim, Novartis and Gebro, Speakers bureau: ND, Cesar Díaz-Torné: None declared, Ana Laiz Consultant for: Lilly, Novartis, AbbVvie, MSD, UCB and Janssen, Speakers bureau: Lilly, Novartis, Abvvie, MSD, UCB and Janssen, Patricia Moya None declared, Ana Milena Millán Arciniegas: None declared, Andrea García-Guillén: None declared, Sycille Jeria: None declared, DAVID LOBO: None declared, Susana P. Fernandez-Sanchez: None declared, CONXITA PITARCH: None declared, MANEL RIERA: None declared, MARIA CARMEN HERNANDEZ LAFUENTE: None declared, Cándido Juarez: None declared, Hector Corominas: None declared DOI: 10.1136/annrheumdis-2019-eular.5153

\section{THU0275 NEW PROSPECTIVE OF COGNITIVE IMPAIRMENT IN SYSTEMIC LUPUS ERYTHEMATOSUS PATIENTS: A PRAGMATIC LANGUAGE EVALUATION}

Carmelo Pirone $^{1}$, Fulvia Ceccarelli ${ }^{1}$, Concetta Mina ${ }^{2}$, Alfredo Mascolo ${ }^{3}$, Carlo Perricone ${ }^{1}$, Barbara Mazzotta ${ }^{1}$, Laura Massaro ${ }^{1}$, Francesca Spinelli ${ }^{1}$, Cristiano Alessandri ${ }^{1}$, Guido Valesini ${ }^{1}$, Fabrizio Conti ${ }^{1}$. ${ }^{1}$ Sapienza Università di Roma, Lupus Clinic, Dipartimento di Medicina Interna e Specialità Mediche, Roma, Italy; ${ }^{2}$ Sapienza Università di Roma, Dipartimento di Neurologia e Psichiatria, Roma, Italy, ${ }^{3}$ Università degli studi di Roma Tor Vergata, Dipartimento di Neuroscienze, Clinica Neurologica, Roma, Italy

Background: Cognitive impairment $(\mathrm{Cl})$ in Systemic Lupus Erythematosus (SLE) is a frequent neuropsychiatric manifestation affecting severa domains, even in apparently asymptomatic patients. Current research revealed that the typical $\mathrm{Cl}$ pattern affects frontal-subcortical circuit and thus executive functions. The impairment of non-literal language or Prag matic Language $(\mathrm{PL})$, including metaphors, idioms, inferences or irony has been well described in several conditions such as autism disorders, Parkinson's disease, brain injury and even in earlier phases of neurodegenerative processes. Even if $\mathrm{PL}$ neuro-anatomy remains controversial, correlation between executive dysfunctions and non-literal language involvement has been reported both in traumatic injury and mild cognitive impairment patients. Nonetheless, no specific study has been performed to evaluate $\mathrm{PL}$ impairment in SLE patients so far.

Objectives: We aimed at assessing the $\mathrm{PL}$ domain in a monocentric SLE cohort in comparison to healthy controls, matched to age and edu cation, through a specific battery, BLED [1]. Secondly, we focused attention on possible correlations between $\mathrm{Cl}$ and clinical and laboratory SLErelated features.

Methods: Forty adult patients affected by SLE, according to the ACR criteria, and thirty healthy subjects were enrolled consecutively in this crosssectional study. The protocol included complete physical examination extensive clinical and laboratory data collection (comprehensive of demographics, past medical history, co-morbidities, disease activity, chronic damage evaluation, previous and concomitant treatments) and cognitive assessment for five different domains: memory, attention, pragmatic language, executive and visuospatial functions. Self-reported scale for anxiety and depression were performed to exclude the influence of mood disorders on cognitive dysfunction.

Results: We enrolled forty Caucasian SLE patients (M/F 3/37; mean $\pm S D$ age $45.9 \pm 10.1$ years, mean $\pm S D$ disease duration $120.8 \pm 81.2$ months) and thirty healthy subjects $(\mathrm{M} / \mathrm{F} 9 / 21$; mean $\pm S D$ age $41.3 \pm 13$ years). According to the low level of disease activity and damage (mean \pm SD SLEDAI$2 \mathrm{~K}$ of $1.3 \pm 2.3$, mean $\pm S D$ SDI of $0.2 \pm 0.5)$, only $30 \%$ of patients was on glucocorticoid treatment at the study entry. PL was the most compromised domain in terms of Mean Domain Z scores (Fig. 1). As regards the Domain Cognitive Dysfunction score, a deficit of $\mathrm{PL}$ was observed in $45 \%$ of patients and resulted significantly more prevalent than memory executive and visuospatial functions impairment $(P=0.0002, P=0.0002$ and $\mathrm{P}<0.000001$, respectively). According to Global Cognitive Dysfunction score $25 \%$ of patients experienced a mild impairment and $7.5 \%$ a moderate one. Anti-phospholipid antibodies positivity was significantly associated with memory impairment $(\mathrm{P}<0.0005)$, whereas the presence of other neu ropsychiatric events was associated with executive dysfunctions $(P<0.05)$; neither further significant association nor correlation were identified. 